\title{
Abrogating HSP Response Augments Cell Death Induced by As2O3 in Glioma Cell Lines
}

\author{
Xueming Song, Zhiqiang Chen, Chunbo Wu, Shiguang Zhao
}

\begin{abstract}
Objectives: We previously reported that Arsenic trioxide (ATO) can inhibit glioma growth both in vitro and in vivo. While the use of ATO alone for solid tumor treatment sometimes was found to be ineffective which may be due to the protective pathways including heat shock proteins (HSPs) response induced by ATO. In this study, we modified HSPs expression to investigate whether HSPs had some effect on ATO induced glioma cell death. Methods: Trypan bule exclusion assay, mitochondrial membrane potential (MMP) Assay, and SubG1 detection were used to evaluate cell viability and western-blot was employed to detect HSPs and some apoptosis markers expression induced by ATO. Heat pre-treatment, HSPs inhibitor, or Heat Shock factor-1 (HSF1) knockdown by SiRNA was employed to modify HSPs levels. Results: It was showed that KNK437 (HSPs inhibitor) or HSF1 knockdown significantly enhanced cell death, MMP disruption, JNK phosphorylation and caspase-3 cleavage induced by ATO, which was accompanied by abrogation of HSPs induction, while heat pre-treatment with clear HSPs induction had strong protection on the effects mentioned above. Conclusion: Those data suggested that HSPs play protective roles on ATO induced cell death in glioma. Inhibition of HSPs may have a synergistic effect with ATO on glioma treatment.
\end{abstract}

RÉSUMÉ: La suppression de la réponse HSP augmente la mort cellulaire induite par As203 dans les lignées cellulaires de gliomes. Objectifs : Nous avons rapporté antérieurement que le trioxyde d'arsenic (TOA) peut inhiber la croissance de gliomes tant in vitro qu'in vivo. Cependant, l'utilisation du TOA seul pour le traitement de tumeurs solides s'avérait parfois inefficace, ce qui pourrait être dû aux voies protectrices telles la réponse aux protéines de choc thermique (HSP) induite par le TOA. Dans cette étude, nous avons modifié l'expression des HSP pour déterminer si les HSP avaient un effet sur la mort de cellules de gliomes induite par le TOA. Méthodes : Le test d'exclusion au bleu trypan, le test de potentiel membranaire mitochondrial (PMM) et la détection de cellules en phase Sub-G1 ont été utilisés pour évaluer la viabilité cellulaire, et le buvardage de western pour détecter les HSP et l'expression de certains marqueurs de l'apoptose induits par le TOA. Nous avons utilisé le pré-traitement par la chaleur, l'inhibition des HSP ou l'inactivation du heat-shock factor 1 (HSF1) par ARNsi pour modifier les niveaux de HSP. Résultats : Nous avons observé que le KNK437, un inhibiteur des HSP, ou l'inhibition d'HSF1 augmentait significativement la mort cellulaire, la perturbation du PMM, la phosphorylation de JNK et le clivage de la caspase 3 induit par le TOA qui est accompagné par la suppression de l'induction des HSP Par contre, le prétraitement par la chaleur avec une induction évidente des HSP conférait une protection efficace contre les effets ci-haut mentionnés. Conclusion : Ces données suggèrent que les HSP jouent un rôle protecteur contre la mort cellulaire induite par le TOA dans le gliome. Il est possible que l'inhibition des HSP ait un effet synergique à celui du TOA dans le traitement du gliome.

Can. J. Neurol. Sci. 2010; 37: 504-511

Malignant gliomas are the most common and lethal tumors of the central nervous system and are resistant to many kinds of treatment, including radiation, chemotherapy, and other adjuvant therapies $^{1,2}$. Although considerable progress has been made in the treatment of glioma, its prognosis is still very poor ${ }^{3}$. The inefficacy of these therapeutic modalities in curing gliomas is due to the resistance of glioma cells and the difficulty of achieving complete tumor resection. There is therefore an urgent need to devise alternative therapeutic strategies to combat gliomas.

We previously reported that Arsenic Trioxide (As2O3, or ATO) can inhibit glioma growth both in vitro and in vivo ${ }^{4-6}$, which demonstrated the potent therapeutic effects of this drug.
Arsenic Trioxide has complex effects on many biological systems, including generation of reactive oxygen species, induction of DNA damage, disruption of mitochondrial function, modification of gene and/or protein expression and intracellular

From the Department of Neurosurgery, 1st Affiliated Hospital of Harbin Medical University, Nangang District, Harbin, P.R. China.

Received October 8, 2010. Final Revisions Submitted January 11, 2010. Correspondence to: Shiguang Zhao, Department of Neurosurgery, 1st Affiliated Hospital of Harbin Medical University. No 23, Youzheng Street, Nangang District, Harbin, P.R. China, 150001 
signal transduction pathways, alteration of cell cycle progression, and induction of cytogenetic aberrations and cellular transformation ${ }^{7-10}$, thus triggering apoptosis. Nevertheless, the use of ATO alone for solid tumor treatment sometimes was found ineffective at small dose while increasing its amount leads to toxicity ${ }^{11}$. Some reports even pointed out that small doses of ATO promotes cancer growth and angiogenesis ${ }^{12}$. The ineffectiveness of the drug may be due to the fact that Arsenite induces a variety of cellular stress which may activate some protective pathways including heat shock proteins (HSPs) induction, heme oxygenase-1 (HO-1) induction, NF- $x \mathrm{~B}$ activation, and $\mathrm{etc}^{13}$. It is reasonable to speculate that combination with some other strategies to abrogate ATO induced protective mechanisms may augment its therapeutic role in glioma therapy and reduce its cytoxic effects.

Arsenite can induce HSPs expression in a variety of cells ${ }^{14,15}$. HSPs are molecular chaperones which help protein folding and transportation ${ }^{16,17}$. Such function as chaperone molecules confers a protective role for maintaining cellular homeostasis under a variety of stress including chemical, oxidative and thermal injuries $^{18-20}$. Moreover, HSP70 (also named as HSP72) inhibits apoptosis pathways ${ }^{21,22}$, thus protecting cells from multianticancer therapies ${ }^{23}$. Therefore, targeting heat shock proteins may enhance anti-glioma treatment mediated by ATO. So far, there is no study related to ATO combined with HSPs inhibition in gliomas. In this study we demonstrate the augmentation of ATO induced cell death by HSPs abrogation in glioma cell lines.

\section{Materials ANd Methods}

\section{Cell culture}

The human glioma cell lines, U251MG and T98G, and human lung cancer cell lines A549 obtained from RIKEN Cell Bank (Tsukuba Science City, Japan) were maintained in DMEM (Sigma) with $10 \%$ Fetal Bovine Serum. To evaluate viability, cells were mixed with the same volume of $0.4 \%$ Trypan blue solution, and immediately examined to determine whether they excluded the dye under light microscopical observation.

\section{Reagents and antibodies}

An As2O3 solution was purchased from the Department of Pharmacy in the First Clinical Medical School of Harbin Medical University (Harbin, China), using fresh dilutions with medium for each experiment. Anti-JNK1, anti-HSP70, antiHSP40, anti- $\beta$-actin and anti-caspase-3 antibodies were purchased from Santa Cruz Biotechnology Inc. (Santa Cruz, CA, USA). Anti-P-JNK antibody was from Promega Corp. (Madison, WI, USA). Heat shock protein inhibitor KNK437 was from Kaneka Corp (Takasago, Japan).

\section{Heat shock}

Culture dishes containing exponentially growing cells were immersed in a water bath (Thermominder EX; Taitec Co., Ltd, Koshigaya, Japan) maintained at $42^{\circ} \mathrm{C}$. After a preheating treatment of 30 minutes, the cells were cooled down immediately and then incubated at $37^{\circ} \mathrm{C}$ in a humidified $\mathrm{CO} 2$ incubator. Under the present experimental conditions, no marked change in $\mathrm{pH}$ values was detected in the medium during the treatment.

\section{Small RNA interference}

The 21-nt duplex small interfering RNA pools for HSF1 (siGENOME SMARTpool M-010021), and control siRNAs (random: 5'-NNACTCTATCTGCACGCTGAC-3') were purchased from Dharmacon (Lafayette, CO, USA). Cells $\left(1 \times 10^{5}\right.$ cells per well in a 12-well plate) were incubated for 24 hours, and transfected twice ( $80 \mathrm{nmol}$ each) using Lipofectamine RNAiMAX (Invitrogen). After two days, cells were used for the analysis for western blots and cell viability. Transfection efficiency (usually $>50 \%$ ) was assessed in parallel wells by transfection with pEGFP expression vector (BD Biosciences Clontech, Mountain View, CA, USA).

\section{Detection of mitochondrial membrane potential (MMP)}

Following treatment, cells were incubated with DePsipher solution (Trevigen, Gaithersburg, MD, USA) for 20 minutes in cell culture incubator (from light), after which they were washed with PBS, resuspended with reaction buffer, MMP was immediately determined using a FACScan flow cytometer (Becton Dickinson, Mountain View, CA, USA). DePsipher is a lipophilic cation, which aggregates upon membrane polarization and forms an orange-red fluorescent compound. Mitochondrial membrane potential disruption blocks aggregation of DePsipher, which reverts to its green monomeric green fluorescent form. Thus, a decrease of the fluorescent signals (FL2) indicates loss of MMP.

\section{SubG1 detection}

After treatment, cells were detached by trypsin, washed in PBS then incubated with $0.1 \%$ Triton X-100 for ten minutes, washed, further incubated with $25 \mathrm{ug} / \mathrm{mL}$ propidium iodide, and $1 \mathrm{ug} / \mathrm{mL}$ RNase A for 15 minutes and analyzed for cellular fluorescence by FACScan flow cytometry (Becton Dickinson, Mountain View, CA) using CellQuest Software.

\section{Western blotting}

After washing with ice-cold PBS, cells were lysed by adding $200 \mathrm{ml}$ of RIPA buffer (100mM NaCl, 2mM EDTA, 1mM PMSF, $1 \% \mathrm{NP}-40$ and 50mM Tris- $\mathrm{HCl}$ ( $\mathrm{pH} 7.2)$ ). Total cell lysates were collected and their protein concentration was evaluated using a protein assay (Bio-Rad, Melville, NY, USA).The lysates $(20 \mathrm{mg}$ per lane) were separated by 10-15\% SDS-PAGE gels and then transferred to PVDF membranes (Millipore, Bedford, MA, USA) at $20 \mathrm{~V}$ for 50 minutes. Membranes were soaked in $5 \%$ bovine serum albumin (Sigma) overnight. The membranes were incubated with primary antibodies overnight at $41 \mathrm{C}$, and thereafter incubated with the corresponding peroxidase-linked secondary antibodies (Amersham or MBL) for one hour at room temperature. Signals were developed by a standard enhanced chemiluminescence method following the manufacturer's protocol (Amersham)

\section{Statistical analysis}

The data were expressed as the mean \pm SD. Statistical analysis was evaluated using Student's t-test (SPSS program version 10.1; SPSS, San Rafael, CA, USA). $\mathrm{P}<0.05$ was considered statistically significant. 


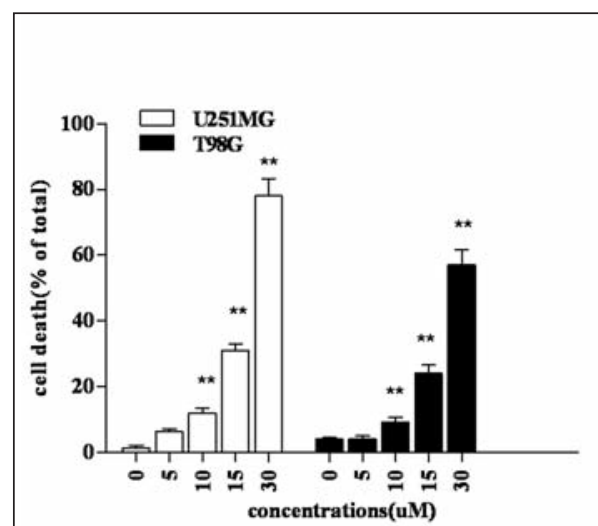

A
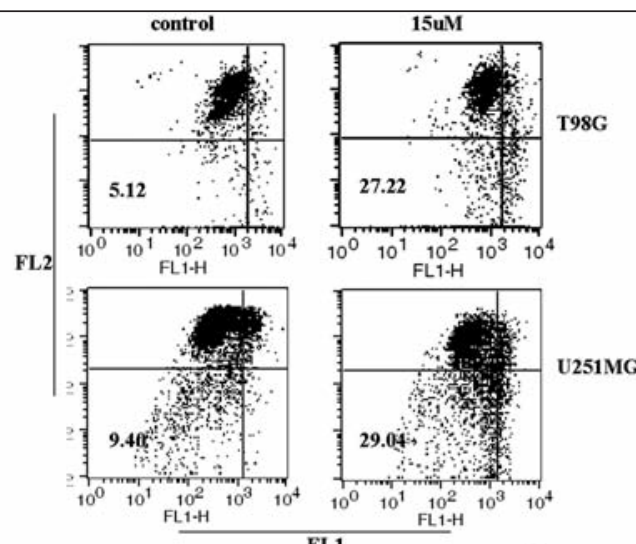

B
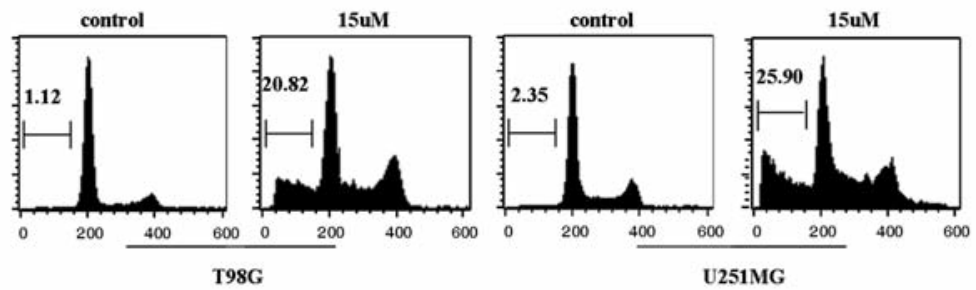

C

Figure 1: ATO induced cell death in glioma cell lines. (A). Trypan blue exclusion assay showed cell death fraction at $24 \mathrm{~h}$ after ATO exposure (uM) in $U 251 M G$ (open bars) and T98G (closed bars). Error bars indicate the mean $\pm S . D$. of data from three separate experiments. $* * P<0.01$ compared with control cells. (B). Loss of mitochondrial membrane potential (MMP). Cells were treated with 15uM ATO for $24 \mathrm{~h}$, then incubated with Depsipher solution and intracellular fluorescence was detected by flow cytometer. Numbers indicate \% of cells showing loss of MMP. (C). SubG1 population. U251MG and $T 98 G$ cells were similarly treated as (B), and DNA content in each cell was detected by flow cytometer after incubation of propidium iodide. Numbers indicate \% of sub-G1 population.

\section{RESULTS}

\section{ATO induced cell death in glioma cells}

To determine the therapeutic effect of ATO on glioma cells, we performed cell death experiments using human glioma cell lines U251MG and T98G. After 24 hours exposure to ATO, cell death happened by a dose-dependent manner in both cell lines. As shown in Figure 1A, cell death fraction analyzed by trypan blue exclusion assay gradually increased when the concentration of ATO increased from 5-30uM. At concentration of $15 \mathrm{uM}$, ATO induced $31 \%$ of cell death in U251MG and $24 \%$ in T98G, respectively. Mitichondrial membrane potential disruption is a prerequisite step toward programmed cell death ${ }^{24}$. Treatment with 15uM ATO resulted in distinct MMP loss, which is $29.04 \%$ in $\mathrm{U} 251 \mathrm{MG}$ and $27.22 \%$ in $\mathrm{T} 98 \mathrm{G}$, respectively (Figure 1B). Apoptotic fraction was also shown by SubG1 ratio after ATO exposure, which revealed that ATO induced cell death in the two cell lines was mainly due to apoptosis (Figure 1C) since SubG1 ratio was consistent with trypan blue assay and MMP loss.

\section{ATO induced both apoptotic markers and heat shock proteins in glioma cell lines}

Arsenic trioxide induces a variety of cellular stress, which may activate both apoptosis signal and protective pathways including heat shock proteins induction ${ }^{13}$. We detected apoptosis markers and heat shock proteins by western blot after ATO treatment (Figure 2). Arsenic trioxide at 15uM clearly induced

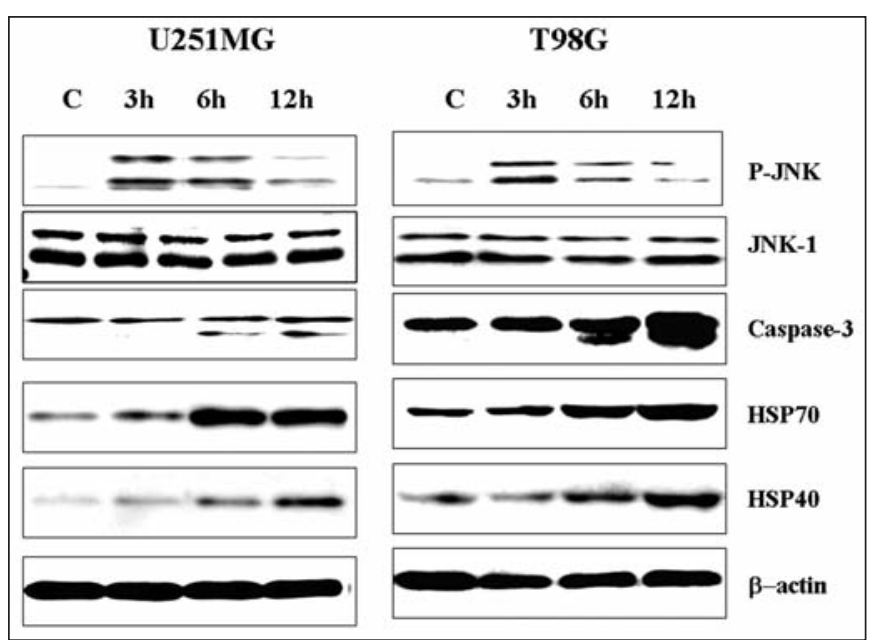

Figure 2: ATO induced both apoptotic markers and heat shock proteins in glioma cell lines. Total cell lysates were harvested after incubation with 15 uM ATO for indicated hours. JNK activation, caspase-3 cleavage, Hsp70 and HSP4O were evaluated by western blot using anti-phosphoJNK, anti-caspase-3, anti-HSP7O and anti-HSP4O antibodies. Same membranes were re-blotted by anti-JNK1 and anti- $\beta$-actin antibodies to show equal protein loadings. 


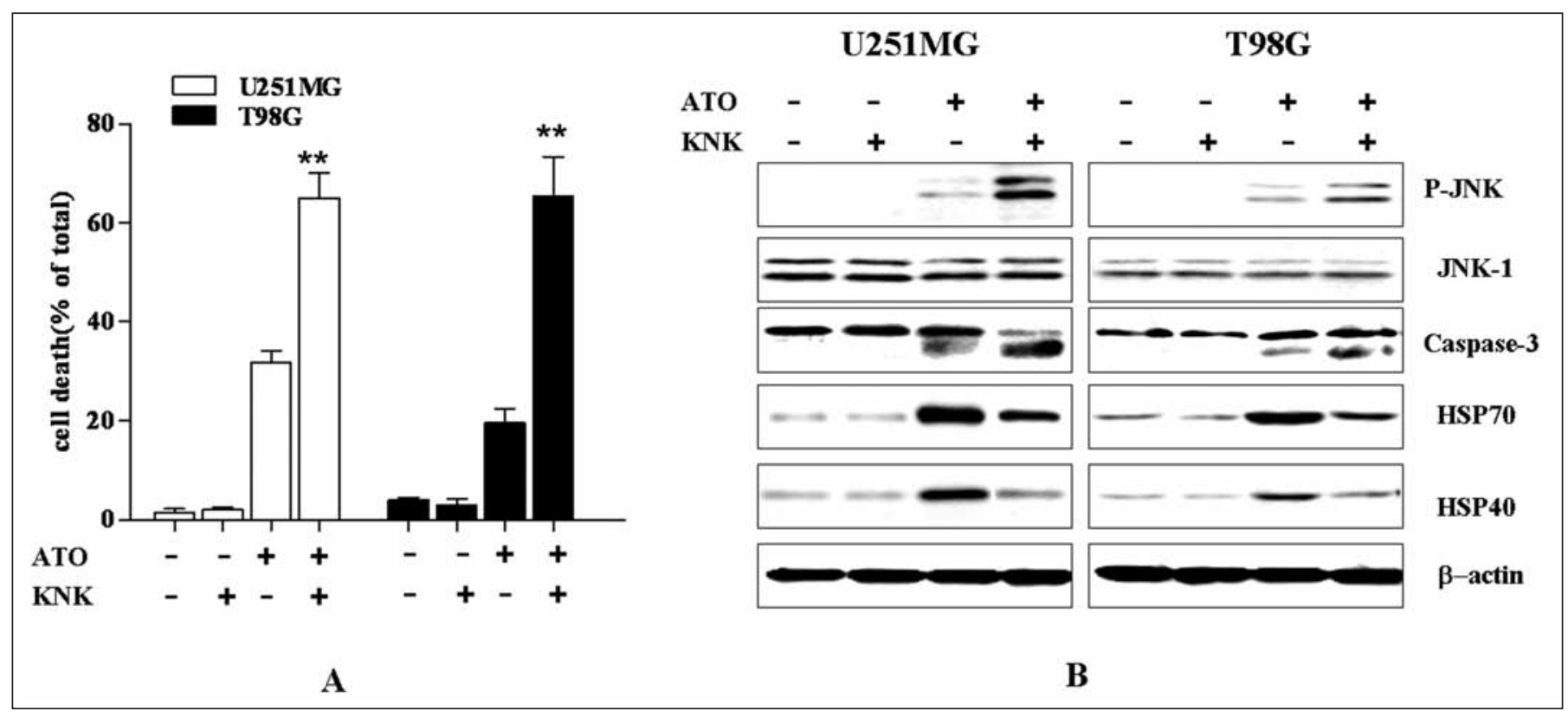

Figure 3: Heat shock protein response inhibitor, KNK437, enhanced ATO induced cell death in glioma cells. (A).Trypan blue exclusion assay. Cell death fraction at $24 \mathrm{~h}$ after ATO (15uM) incubation with or without KNK437 pretreatment (100uM $2 \mathrm{~h}$, no washing). Error bars indicate the mean \pm S.D. of data from three separate experiments. $* * P<0.01$ compared with KNK437 untreated cells. (B). Induction of apoptotic markers and heat shock proteins. After incubation with 15 MM ATO for 6 hours with or without KNK437 pretreatment, JNK activation, caspase-3 cleavage, Hsp70 and HSP 40 were evaluated by western blot using anti-phospho-JNK, anti-caspase-3, anti-HSP70 and anti-HSP4O antibodies. Same membranes were re-blotted by anti-JNK1 and anti- $\beta$-actin antibodies to show equal protein loadings.

apoptosis signals in glioma cells. C-Jun N-terminal kinase (JNK) phosphorylation and caspase-3 cleavage were clearly induced after ATO exposure. C-Jun N-terminal kinase phosphorylation happened as early as three hours after treatment, then gradually decreased at 6 hours and at 12 hours. Compared with JNK phosphorylation, caspase- 3 cleavage was a late event which happened at 6 hours and increased at 12 hours. Meanwhile, HSP70 and HSP40 were strongly induced 6 hours after ATO exposure and continued to 12 hours. These results indicate that ATO simultaneously activated both cell death pathways and HSPs which confer protective role for cell survival.

\section{Heat shock protein response inhibitor, KNK437, enhanced ATO induced cell death in glioma cells}

It is well known that HSPs induction protects cells from a variety kinds of cellular stress. We explored whether inhibition of HSPs induction can enhance the cytotoxic effects of ATO in glioma cells. Trypan blue exclusion assay showed that pretreatment of KNK437 (100uM $2 \mathrm{~h}$, no washing), which is a kind of heat shock protein synthesis inhibitor ${ }^{9}$, strongly increased ATO induced cell death in both U251MG and T98G cell lines while KNK437 alone had no effect on cell viability under the indicated concentration in our experiment (Figure 3A). We also detected apoptosis markers and HSPs induction 6h after $15 \mathrm{uM}$ ATO exposure with or without KNK437 pretreatment. Western blot results (Figure 3B) demonstrated that KNK437 strongly enhanced JNK -phosphorylation and caspase-3 cleavage induced by ATO with clear inhibition of HSP70 and HSP40 induction, while it alone had no effects on those markers. These results suggest that heat shock protein inhibition may have synergistic effect with ATO on glioma cells.

\section{Sublethal heat shock pretreatment abrogated ATO induced cell death in glioma cells}

We further investigated whether HSPs induction can protect ATO induced cell death. Sublethal heat shock $\left(42^{\circ} \mathrm{C} 30\right.$ minutes $)$ strongly induced HSP70 and HSP40 expression (Figure 4A). Trypan blue exclusion assay showed that heat shock pretreatment had no effect on cell viability while clearly canceled ATO induced cell death in both cell lines (Figure 4B). Slimilar results were obtained by MMP assay (data not shown) that heat pre-treatment strongly protected MMP loss against ATO treatment with minor influence on cell viability when administered alone. Apoptosis markers detection revealed that sublethal heat shock pretreatment strongly inhibited JNKphosphorylation and caspase- 3 cleavage induced by ATO (Figure 3B). The results suggest that heat shock proteins may have protective effects on ATO induced cell damage.

\section{HSF1 knockdown enhanced ATO's therapeutic effects}

Heat shock proteins are mainly regulated by heat shock factor-1 (HSF1) which translocates into nucleus and binds to heat shock element after activation thus initiate HSPs 
transcription $^{25}$. To further confirm heat shock proteins' role after ATO treatment, we employed HSF1-siRNA SMARTpool transfection in U251MG, which substantially decreased HSF1 protein level (Figure 5A). Then we compared the sensitivity of Si-random and Si-HSF1 cells to ATO. Trypanblue exclusion assay (Figure 5A) and Mitichondrial membrane potential dection (Figure 5B) demonstrated that HSF1 knockdown had no effect on cell viability by itself while strongly increased ATO induced cell death. Western blot results (Figure 5C) revealed that HSF1 knockdown clearly enhanced JNK activation and caspase-3 cleavage induced by ATO with inhibition of HSPs induction. In order to clarify whether the protective effect of HSF1-HSPs is universal, we performed similar experiments in human lung cancer cell line A549, which revealed that HSF1 knockdown clearly enhanced cell death induced by ATO (Figure 5D).

\section{DISCUSSION}

Arsenic trioxide may induce apoptosis, autophagy, and necrosis in cancer cells ${ }^{5}$. Our results showed that ATO induced cell death under the current conditions mainly via apoptosis since SubG1 ratio was consistent with trypan blue assay and MMP loss. Our data also showed that HSPs inhibitor KNK437 strongly inhibited ATO induced HSPs induction and enhanced cell death and apoptotic markers. We then performed sublethal heat shock pretreatment, an easy approach to upregulate HSPs with minor influence on cell viability, prior to ATO exposure, which resulted in significant protection to ATO. Those results suggested that HSPs play important roles on ATO induced cell damage. Furthermore, we comfirmed such effects of HSPs by knockdown of HSF1 by SiRNA, similar to KNK437, which strongly increased ATO's cytotoxic effects on glioma cells. Our

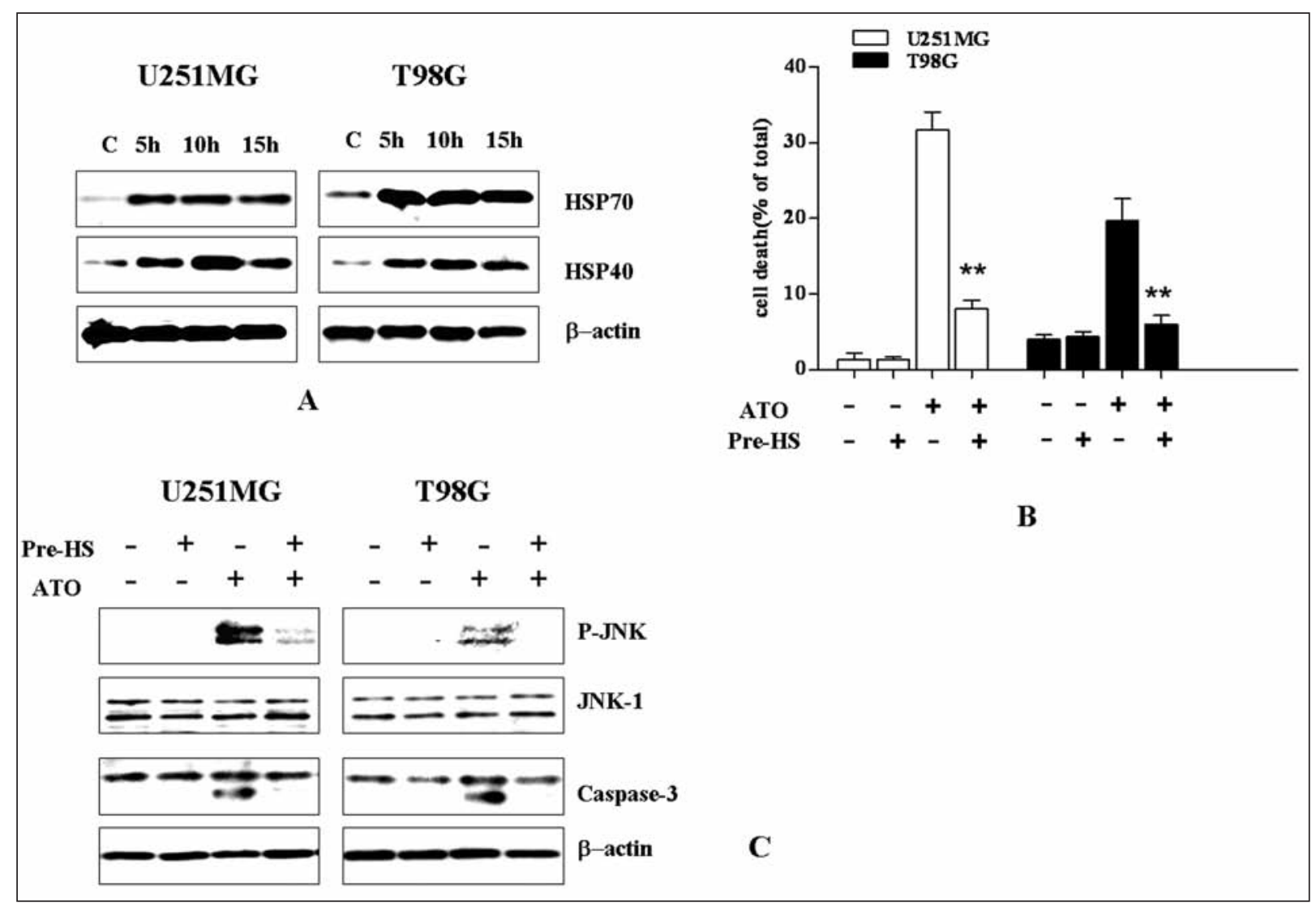

Figure 4: Sublethal heat shock pretreatment abrogated ATO induced cell death in glioma cells. (A). Western blot. Heat shock proteins induction at indicated hours after heat shock of 30 minutes at $42{ }^{\circ} \mathrm{C} . \mathrm{Hsp} 70$ and HSP 40 were evaluated by western blot using anti-HSP70 and anti-HSP4O antibodies. Same membranes were re-blotted by anti- $\beta$-actin antibody to show equal protein loadings. (B). Trypan blue exclusion assay. Cell death fraction at $24 \mathrm{~h}$ after ATO $(15 \mathrm{uM})$ incubation with or without heat shock pretreatment $\left(30\right.$ minutes at $\left.42^{\circ} \mathrm{C}\right)$ which was performed 10 hours before ATO incubation. Error bars indicate the mean $\pm S . D$. of data from three separate experiments. $* * P<0.01$ compared with heat shock untreated cells. $(C)$. Apoptotic markers induction. Total cell lysates were harvested 6 hours after ATO $(15 \mathrm{uM})$ incubation with or without heat shock pretreatment $\left(30\right.$ minutes at $\left.42^{\circ} \mathrm{C}\right)$ which was performed 10 hours before ATO incubation. JNK activation and caspase-3 cleavage were evaluated by western blot using anti-phospho-JNK and anti-caspase-3 antibodies. Same membranes were re-blotted by anti-JNK1 and anti- $\beta$-actin antibodies to show equal protein loadings. 


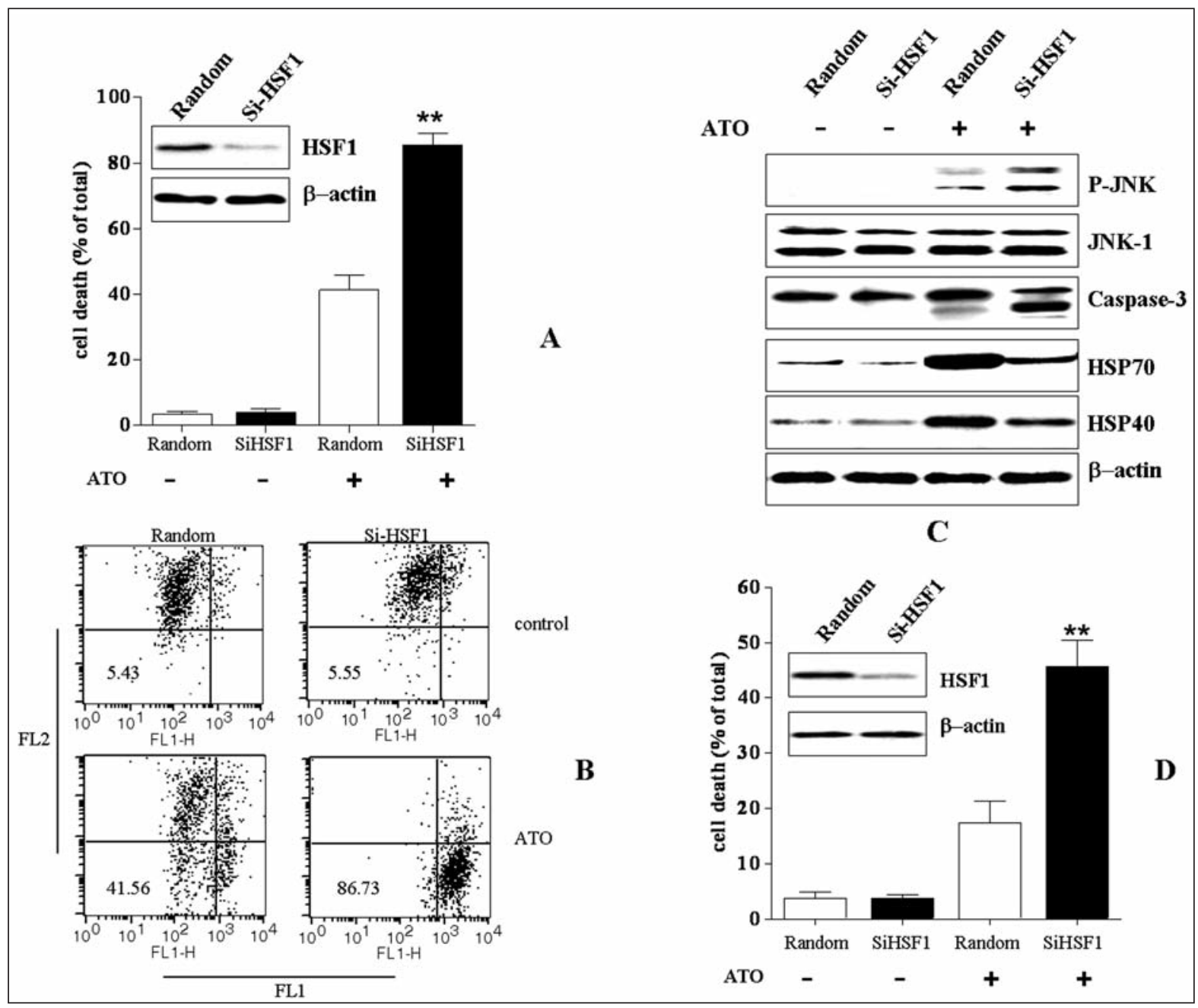

Figure 5: . HSF1 knockdown enhanced ATO induced cell death. (A) Trypan blue exclusion assay 48 hours after transfection with SiRandom or SiHSF1, U251MG cells were exposed to 15 MM ATO for $24 \mathrm{~h}$. HSF1 knockdown was evaluated by western blot analysis. Error bars indicate the mean $\pm S$.D. of data from three separate experiments. $* * P<0.01$ compared with SiRandom transfectants. $(B)$. Loss of mitochondrial membrane potential (MMP). After transfection as (A), cells were treated with $15 \mathrm{uM}$ ATO for $24 \mathrm{~h}$, then incubated with Depsipher solution and intracellular fluorescence was detected by flow cytometer. Numbers indicate \% of cells showing loss of MMP. $(C)$. Apoptotic markers and heat shock proteins induction. After transfection as $(A)$, cells were treated with 15 uM ATO for 6h, JNK activation, caspase-3 cleavage, Hsp70 and HSP40 were evaluated by western blot using anti-phospho-JNK, anti-caspase-3, anti-HSP70 and anti-HSP4O antibodies. Same membranes were re-blotted by anti-JNK1 and anti- $\beta$-actin antibodies to show equal protein loadings. (D). Trypan blue exclusion assay 48 hours after transfection with SiRandom or SiHSF1, A549 cells were exposed to $15 \mathrm{uM}$ ATO for $24 \mathrm{~h}$. HSF1 knockdown was evaluated by western blot analysis. Error bars indicate the mean $\pm S . D$. of data from three separate experiments. ${ }^{* * P}<0.01$ compared with SiRandom transfectants.

findings provided a new strategy for glioma's chemotherapy by combination of HSPs inhibition with ATO.

Arsenic trioxide is considered as a potent anti-cancer drug and it has complex effects on a variety of biological systems, including generation of reactive oxygen species, disruption of mitochondrial function, induction of DNA damage, modification of gene and/or protein expression and intracellular signal transduction pathways, alteration of cell cycle progression, and induction of cytogenetic aberrations and cellular transformation $^{7-10}$, thus triggering apoptosis. While its application is limited for the inefficacy at small dose and toxicity at large administration ${ }^{11}$. As a stress inducer, ATO also activates some protective pathways including heat shock proteins induction, heme oxygenase- 1 induction, NF- $x \mathrm{~B}$ activation, and etc $^{13}$, which may abrogate its anti-cancer effects.

Heat shock proteins are a group of proteins that are rapidly induced in response to events of physiological stress, including elevated temperatures, metals, drugs, hypoxia and conditions resulting in oxidative stress ${ }^{24-26}$. The cellular response to arsenic shares many similar features with oxidative stress response and the heat shock response. Both heat stress and arsenic exposure induce the heat shock proteins, and initiate signal transduction 
cascades ${ }^{27}$. As chaperones HSPs confer protection to many kinds of stress ${ }^{18-20}$. Arsenite induces HSPs via activation of HSF1, thus small dose of arsenite has a tumor growth promotion effect which can be enhanced by moderate heat shock ${ }^{28}$. Our results also showed that ATO clearly induced HSPs and inhibition of which enhanced ATO induced cell death and apoptosis markers in glioma cells. Furthermore, sublethal heat induced HSPs strongly inhibited ATO induced cell death. Those data indicate that HSPs provide significant protection against ATO exposure.

We here attempted to understand protective role of HSPs induction by ATO. Several reports showed that Hsp70, also named as HSP72, can inhibit JNK activity and thereby inhibit JNK-mediated apoptosis ${ }^{29-31}$. Someone pointed out Hsp70 reduces the JNK activity by increasing the rate of its dephosphorylation $^{32,33}$. Our results also showed ATO induced JNK phosphorylation decreased after HSPs induction (Figure 2). Inhibition of HSPs or knockdown of HSF1 strongly inhibited HSPs induction and increased JNK phosphorylation. Moreover, Pre-heat induced significant HSPs expression and strongly inhibited JNK phosphorylation.

Another possible mechanism of HSPs' protective effect on apoptosis is its prevention of cytochrome c release ${ }^{22}$. Our results demonstrated Pre-heat blocked ATO induced mitochondrial membrane potential disruption and caspase- 3 cleavage while HSPs inhibition enhanced the above markers induced by ATO. Possibly ATO induced HSPs can stablize mitochondrial membrane thus prevented cytochrome $\mathrm{c}$ release and blocked its downstream pathways.

\section{Conclusion}

In summary, ATO is a potent anti-cancer drug which has complex effects on many biological systems. Blockade of the protective pathways induced by ATO may enhance its therapeutic effects on glioma. Our findings for the first time demonstrated that inhibition of HSPs induction has synergistic effects with ATO on glioma treatment.

\section{ACKNOWLEDGEMENTS}

This Research was supported by the National Natural Science Foundation of China (No. 30772239), Foundation of Harbin Science and Technology Committee (No. 2007AA3CS083-2), and Foundation of Heilongjiang Natural Science Foundation(No. D2004-26).

\section{REFERENCES}

1. Berger F, Gay E, Pelletier L, Tropel P, Wion D. Development of gliomas: potential role of asymmetrical cell division of neural stem cells. Lancet Oncol. 2004;5(8):511-4.

2. Carpentier AF. Neuro-oncology: the growing role of chemotherapy in glioma. Lancet Neurol. 2005;4(1):4-5.

3. Jeong M, Kwon YS, Park SH, Kim CY, Jeun SS, Song KW, et al. Possible novel therapy for malignant gliomas with secretable trimeric TRAIL. PLoS One. 2009;4(2):e4545.

4. Zhao S, Zhang X, Zhang J, Zhang J, Zou H, Liu Y, et al. Intravenous administration of arsenic trioxide encapsulated in liposomes inhibits the growth of C6 gliomas in rat brains. J Chemother. 2008;20(2):253-62.

5. Zhao S, Zhang J, Zhang X, Dong X, Sun X. Arsenic trioxide induces different gene expression profiles of genes related to growth and apoptosis in glioma cells dependent on the p53 status. Mol Biol Rep. 2008;35(3):421-9.
6. Zhao S, Tsuchida T, Kawakami K, Shi C, Kawamoto K. Effect of As2O3 on cell cycle progression and cyclins D1 and B1 expression in two glioblastoma cell lines differing in p53 status. Int J Oncol. 2002;21(1):49-55.

7. Simeonova PP, Wang S, Toriuma W, Kommineni V, Matheson J, Unimye $\mathrm{N}$, et al. Arsenic mediates cell proliferation and gene expression in the bladder epithelium: association with activating protein-1 transactivation. Cancer Res. 2000;60(13):3445-53.

8. Miller WH Jr, Schipper HM, Lee JS, Singer J, Waxman S. Mechanisms of action of arsenic trioxide. Cancer Res. 2002;62 (14):3893-903

9. Wu YC, Yen WY, Lee TC, Yih LH. Heat shock protein inhibitors, 17-DMAG and KNK437, enhance arsenic trioxide-induced mitotic apoptosis. Toxicol Appl Pharmacol. 2009;236(2):231-8.

10. Yih LH, Peck K, Lee TC. Changes in gene expression profiles of human fibroblasts in response to sodium arsenite treatment. Carcinogenesis. 2002;23(5):867-76.

11. Dilda PJ, Hogg PJ. Arsenical-based cancer drugs. Cancer Treat Rev. 2007;33(6):542-64.

12. Liu B, Pan S, Dong X, Qiao H, Jiang H, Krissansen GW, et al. Opposing effects of arsenic trioxide on hepatocellular carcinomas in mice. Cancer Sci. 2006;97(7):675-81.

13. Liu J, Kadiiska MB, Liu Y, Lu T, Qu W, Waalkes MP. Stress-related gene expression in mice treated with inorganic arsenicals. Toxicol Sci. 2001;61(2):314-20.

14. Khalil S, Luciano J, Chen W, Liu AY. Dynamic regulation and involvement of the heat shock transcriptional response in arsenic carcinogenesis. J Cell Physiol. 2006;207(2):562-9.

15. Wetzler M, Earp JC, Brady MT, Keng MK, Jusko WJ. Synergism between arsenic trioxide and heat shock protein 90 inhibitors on signal transducer and activator of transcription protein 3 activity-pharmacodynamic drug-drug interaction modeling. Clin Cancer Res. 2007;13(7):2261-70.

16. Arndt V, Rogon C, Höhfeld J. To be, or not to be - molecular chaperones in protein degradation. Cell Mol Life Sci. 2007;64 $(19-20): 2525-41$

17. Picard D. Heat-shock protein 90 , a chaperone for folding and regulation. Cell Mol Life Sci. 2002;59(10):1640-8.

18. Brodsky JL, Chiosis G. Hsp70 molecular chaperones: emerging roles in human disease and identification of small molecule modulators. Curr. Top Med Chem. 2006;6(11):1215-25.

19. Camphausen K, Tofilon PJ. Inhibition of Hsp90: a multitarget approach to radiosensitization. Clin Cancer Res. 2007;13(15 Pt 1):4326-30

20. Jiang B, Xiao W, Shi Y, Liu M, Xiao X. Heat shock pretreatment inhibited the release of Smac/DIABLO from mitochondria and apoptosis induced by hydrogen peroxide in cardiomyocytes and C2C12 myogenic cells. Cell Stress Chaperon. 2005;10(3): 252-62.

21. Beere HM, Wolf BB, Cain K, Mosser DD, Mahboubi A, Kuwana T, et al. Heat-shock protein 70 inhibits apoptosis by preventing recruitment of procaspase-9 to the Apaf-1 apoptosome. Nat Cell Biol. 2000;2(8):469-75.

22. Bivik C, Rosdahl I, Ollinger K. Hsp70 protects against UVB induced apoptosis by preventing release of cathepsins and cytochrome c in human melanocytes. Carcinogenesis. 2007;28 (3):537-44

23. Beere HM. Death versus survival: functional interaction between the apoptotic and stress-inducible heat shock protein pathways. J Clin Invest. 2005;115(10):2633-9.

24. Bross PF, Kane R, Farrell AT, Abraham S, Benson K, Brower ME, et al. Approval summary for bortezomib for injection in the treatment of multiple myeloma. Clin Cancer Res. 2004;10(12 Pt 1):3954-64

25. Westerheide SD, Morimoto RI. Heat shock response modulators as therapeutic tools for diseases of protein conformation. J Biol Chem. 2005;280(39):33097-100.

26. Jolly C, Morimoto RI. Role of the heat shock response and molecular chaperones in oncogenesis and cell death. J Natl Cancer Inst. 2000;92(19):1564-72.

27. Gorman AM, Heavey B, Creagh E, Cotter TG, Samali A. Antioxidant-mediated inhibition of the heat shock response leads to apoptosis. FEBS Lett. 1999;445(1):98-102. 
28. Khalil S, Luciano J, Chen W, Liu AY. Dynamic regulation and involvement of the heat shock transcriptional response in arsenic carcinogenesis. J Cell Physiol. 2006;207(2):562-9.

29. Gabai VL, Meriin AB, Mosser DD, Caron AW, Rits S, Shifrin VI, et al. Hsp70 prevents activation of stress kinases. A novel pathway of cellular thermotolerance. J Biol Chem. 1997;272 (29):18033-7.

30. Gabai VL, Yaglom JA, Volloch V, Meriin AB, Force T, Koutroumanis M, et al. Hsp72-mediated suppression of c-Jun Nterminal kinase is implicated in development of tolerance to caspase-independent cell death. Mol Cell Biol. 2000;20(18): 6826-36.

31. Park HS, Lee JS, Huh SH, Seo JS, Choi EJ. Hsp72 functions as a natural inhibitory protein of c-Jun $\mathrm{N}$-terminal kinase. EMBO J. 2001;20(3):446-56.
32. Volloch V, Gabai VL, Rits S, Force T, Sherman MY. HSP72 can protect cells from heat-induced apoptosis by accelerating the inactivation of stress kinase JNK. Cell Stress Chaperones. 2000;5(2):139-47.

33. Gabai VL, Meriin AB, Yaglom JA, Wei JY, Mosser DD, Sherman MY. Suppression of stress kinase JNK is involved in HSP72mediated protection of myogenic cells from transient energy deprivation. HSP72 alleviates the stress-induced inhibition of JNK dephosphorylation. J Biol Chem. 2000;275(48):38088-94. 